\title{
MIRAgel: the immunohistochemical expression of CD3, CD34, and CD68 in the surrounding capsule
}

M Roldan-Pallares ${ }^{1}$, M LLanes-Estrada ${ }^{2}$

and F LLanes-Menendez ${ }^{2}$

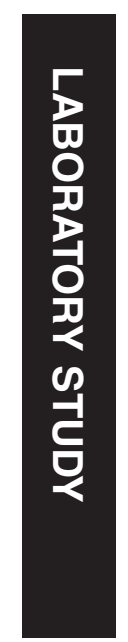

\begin{abstract}
Purpose To study the immunohistochemical features of the capsule tissue surrounding MIRAgel episcleral buckles.

Patients and methods This Institutional interventional clinical cohort study examined a consecutive series of 21 referred patients who required MIRAgel removal from July 2009 to July 2013. All patients with hydrated and fragmented MIRAgel episcleral buckles were included in this study. Capsule biopsies from MIRAgel episcleral buckles were obtained from all patients. Capsule specimens of seven patients with extruded silicone bands were processed as controls. Paraffinembedded specimens were examined using light microscopy and immunohistochemistry (via the PAP horseradish peroxidase technique) to detect the expression of CD3, CD20, CD34 and CD68, and S-100 protein. Results Inflammation with granuloma, which was primarily related to sutures, was found in all $(n=36)$ of the MIRAgel specimens and foreign body granulomas with multinucleated giant cells, histiocytes, and macrophages (CD68+ cells) surrounded the MIRAgel fragments. Average number of CD68+ cells was higher $(P<0.001)$ for MIRAgel than for silicone rubber. The lymphocytic inflammatory infiltrate related to the MIRAgel fragments was CD3+ and CD20- (delayed $T$ cell-mediated immune response). Moderate neoangiogenesis was indicated by the presence of CD34+ cells. Conclusions The immunohistochemical analysis revealed that the immune system is able to identify the fragments of MIRAgel (after its hydrolytic degradation) as a foreign body during a delayed $\mathrm{T}$ cell-mediated immune response. The phagocytosis by macrophages likely triggers and perpetuates local disease. Removal of MIRAgel explants before hydrolysis should be considered.
\end{abstract}

Eye (2016) 30, 1381-1388; doi:10.1038/eye.2016.125; published online 24 June 2016

Introduction

Episcleral bands composed of MAI, a hydrophilic polymer (copoly [methyl acrylate- 2 hydroxyethyl acrylate]) crosslinked with ethylene diacrylate, were introduced in the early 1980s as a superior product to bands composed of solid silicone rubber or silicone sponges for producing scleral buckles. ${ }^{1-3}$

Hydrogel, which was originally known as 'MAI' and subsequently commercialized as 'MIRAgel' (MIRA Inc., Waltham, MA, USA), initially seemed to be the ideal implant material because it has a soft pliable texture and shows low risk of infection ${ }^{1-3}$ at 6 to 53 months after surgery. ${ }^{3}$ However, enthusiasm over its use began to wane in the 1990s because of its unanticipated instability in vivo. ${ }^{4-6}$ An increasing number of reports of the swelling and fragmentation $^{7,8}$ of this buckling material, which produced orbital discomfort and diplopia 7 to 10 years after implantation, led to its discontinuation of use in 1995. Long-term observations revealed hydrogel fragmentation and hydrolytic degradation for both $\mathrm{MAI}^{9}$ and MIRAgel. ${ }^{10}$

Nearly all nonabsorbable biomaterials undergo a progressive encapsulation after implantation in tissues. This phenomenon is also observed with regard to the episcleral explants that are used in retinal detachment (RD) surgery. Encapsulation results in the formation of a fibrous capsule that represents a barrier between the host tissue and the implant material.

The capsule isolates the material and protects it from infection. However, the capsule does not completely protect the implanted material from the changes induced by either mechanical strains or chemical aggression. Previous reports ${ }^{10,11}$ have shown that giant cell granuloma is related
${ }^{1}$ Department of Ophthalmology, Hospital Clinico San Carlos, Facultad de Medicina, Universidad Complutense de Madrid, Madrid, Spain

${ }^{2}$ Department of Pathology, Hospital Clinico San Carlos, Facultad de Medicina, Universidad Complutense de Madrid, Madrid, Spain

Correspondence: M Roldan-Pallares, Department of Ophthalmology, Universidad Complutense de Madrid, Rey Francisco, $11,3^{\circ}, 28008$ Madrid, Spain

Tel: +34 91 5477885;

Fax: +34 690151125 . E-mail: MRPUCMHS@ telefonica.net

Received: 1 November 2015 Accepted in revised form: 4 May 2016 Published online: 24 June 2016 
to hydrogel fragmentation in some hydrogel capsule specimens. In addition, the severe dystrophic calcification of the fibrous capsule was associated with acute and chronic nongranulomatous inflammation in a patient with a hydrogel episcleral buckle extrusion. ${ }^{12}$

To date, the data concerning the immunohistological phenotyping of the inflammatory cells in the MIRAgel capsule tissue have not been made available. This study reports the first immunohistochemical analysis of capsule specimens $(n=36)$ from 21 patients with clinical pseudotumors caused by MIRAgel swelling because of hydrolytic degradation.

\section{Patients and methods}

We studied specimens from the capsule (ie, fibrous tissue) surrounding episcleral MIRAgel using a consecutive series of patients from July 2009 to July 2013.

A total of 42 specimens were collected from 21 patients. These specimens included 36 capsule samples and 6 conjuctiva samples. The specimens were obtained during the removal of the MIRAgel episcleral buckle (EB) under general anesthesia. The surgical technique to remove MIRAgel buckles has been previously reported, ${ }^{13}$ but in this series only BSS (no additional techniques like boric acid or cryo were associated) was used as coadjutant in order to preserve the capsule tissue.

The patients referred to us had limited ocular motility, diplopia, and orbital fullness. Of the patients, 13 were men and 8 were women; the mean age of the patients was 76 years (range, 69-85 years). None of the patients reported any new ocular or systemic disorders (other than systemic hypertension, hypercholesterolemia, or both). The blood laboratory measures (ie, leukocytes, hemoglobin, platelets, antinuclear antibodies (ANAs), and serum $\operatorname{IgA}, \operatorname{IgM}$, and $\operatorname{IgG}$ ) were within normal limits for all the patients.

Magnetic resonance imaging (MRI) was performed in all patients. These scans revealed significant swelling of the MIRAgel surrounding the eye, with a typical imaging appearance of hydrogel fragmentation that consisted of a circumferential orbital mass associated with rim enhancement. ${ }^{14}$

After reviewing our medical records, 16 patients underwent surgery for RD in our Department, with a mean MIRAgel implantation duration of 19 years (range, 16-24 years). Five patients underwent surgery at other hospitals and reported an average MIRAgel implantation duration of 18 years (range, 16-19 years).

All the patients $(n=21)$ had unilateral RDs (12 in their right eyes and 9 in their left eyes) and reported only one surgery to reattach the retina. Of the 21 eyes, 14 underwent cataract surgery several years (mean, 6 years; range, 3-9 years) after retinal reattachment surgery. None of these RDs was initially pseudophakic. Patient visual acuity (VA) before SB removal was between CF (4 patients) and 20/25 (0.8) on the Snellen chart (mean $=20 / 80,0.4$ ). Orbital fullness, pseudotumor, or both were found in all patients with limitated ocular motility and diplopia. There were no cases with extrusion of a MIRAgel buckle. The criteria for buckle removal included morphological, functional, or both types of changes related to the swelling of the MIRAgel material. Before SB removal, the patients were informed about the possibility of scleral perforation during removal, vitreous hemorrhage, RD, persistence of ocular motility disturbance, extensive postoperative inflammation, and decreased vision.

During the study period, 7 patients had extruded silicone bands that required removal. The duration of the episcleral silicone rubber used as cerclage for these patients was 26 months (range, 18-34 months). Capsule specimens $(n=10)$ were obtained-during the removal surgery-and were processed as controls.

All the obtained specimens $(n=52)$ were first fixed for $3 \mathrm{~h}$ in Bouin's fixative. After washing, the specimens were dehydrated in a graded ethanol series, cleared in xylene, and embedded in a Paraplast Plus medium. Serial sections of $5 \mu \mathrm{m}$ thickness were mounted on glass slides and either stained with hematoxylin-eosin (H\&E) and Masson's trichrome or immunostained for CD3 (T cells), CD20 (B cells), CD34 (endothelial cells), and CD68 (macrophages) using commercially available monoclonal antibodies (DAKO, Glostrup, Denmark). Immunostaining for S-100 protein was performed using the DAKO PAP KitTM system (DAKO Corp, Santa Barbara, CA, USA).

The antigens were localized in the sections using the unlabeled antibody peroxidase antiperoxidase technique. ${ }^{15}$ The methodology that is used to localize the antibodies and S-100 protein was performed according to the manufacturer's guidelines.

Positive controls were obtained from the pathology lab. Human melanoma tissue was used as the positive control for S-100 protein. Human tonsillar tissue was used as the positive control for CD34. Osteoarthritis sinovial biopsies were used as the positive controls for CD3, CD20, and CD68. For the negative controls, the primary antibody was eliminated and replaced with PBS.

For the quantitative study, stained cells were first counted in three consecutive microscopic fields $(\times 240)$ and then summed. The mean value was calculated. Student's $t$-test was used to compare the means between groups; a $P$-value of $<0.05$ was considered as significant.

\section{Results}

The capsular tissue $(n=46)$ consisted of dense collagenous bundles with, occasionally, areas of 
fibroadipose tissue. The capsule surrounded the episcleral explants completely. Concentric collagen bundles arranged parallel to the surface of the capsule indicated the interface between the biocompatible material and the surrounding capsule. This phenomenon was observed in 43 specimens (94\%) from 19 patients.

The silicone rubber (10 specimens from 7 patients) capsule specimens consisted of dense fibrous tissue with a smooth and regular interface. The silicone rubber did not exhibit fragmentation in any case. Sutures (Figure 1a) were observed in 5 capsule specimens from 4 patients (4/7 patients, $57 \%$ ). Granuloma and chronic inflammatory cells were found in 3 specimens from 2 patients (2/7 patients, $28.5 \%)$.

The MIRAgel capsule specimens (36 specimens from 21 patients) revealed two groups of histological lesions:

(1) Areas of dense fibrous tissue with scarce neoangiogenesis (CD34+). MIRAgel fragments were found embedded in the capsule tissue in all the MIRAgel capsule specimens $(n=36,100 \%)$. Small MIRAgel fragments were also found embedded in conjunctival tissue (6 specimens from 5 patients; Figure 1b). The hydrogel material appeared as clear areas of an irregular or polygonal shape surrounded by collagen irregularities. MIRAgel fragments were stained with light green, but they were PAS negative. Foreign body granulomas (Figures 1c and d) with multinucleated giant cells, foamy histiocytes, and macrophages (CD68+) surrounding MIRAgel fragments were found in all the specimens $(n=36,100 \%)$ from the 21 patients, as well as areas of mainly lymphocytic (CD3+) infiltration (Figure 2a). CD20+ lymphocytes were not found in these lesions. Few polymorphonuclear leukocytes were observed surrounding the inflammatory infiltrate in 18 specimens (50\%) from 12 patients, revealing some kind of new acute inflammatory process around the old chronic inflammation.

(2) Granulomatous reactions around sutures with polyclonal lymphocytes, histiocytes, and multinucleated


Figure 1 Specimens of capsule (a, c, d) and conjunctiva (b) surrounding a silicone rubber cerclaje (a) and a MIRAgel (b, c, d). In (a), (silicone rubber) no granuloma or inflammation is present and a fragment of Mersilene 4 (0) (Ethicon, LLC, Somerville, NJ, USA) appears on the internal surface of the fibrous capsule (Masson's trichrome $\times 200$ ). In (b), MIRAgel fragments in the conjunctiva are surrounded by granulomas with giant cells $(\mathrm{H} \& \mathrm{E}, \times 200)$. (c) Granuloma surrounding MIRAgel fragments (center of figure) and suture fragments, top right $(\mathrm{H} \& \mathrm{E}, \times 400)$. (d) The phagocytosis of MIRAgel fragments via multinucleated giant cells (Masson's trichrome, $\times 400$ ). 
giant cells. The phagocytosis of small pieces of suture thread was observed in 20 specimens (60\%) from 12 patients. These sutures were easily recognized based on their usual location in the inner layer of the capsule and their refringence under polarized light illumination. When present, the granulomas surrounding the sutures are quiescent and easy to distinguish from the granulomas surrounding the MIRAgel fragments because the two materials are very different microscopically. Scattered metachromatic heparin cells were observed surrounding these granulomas.
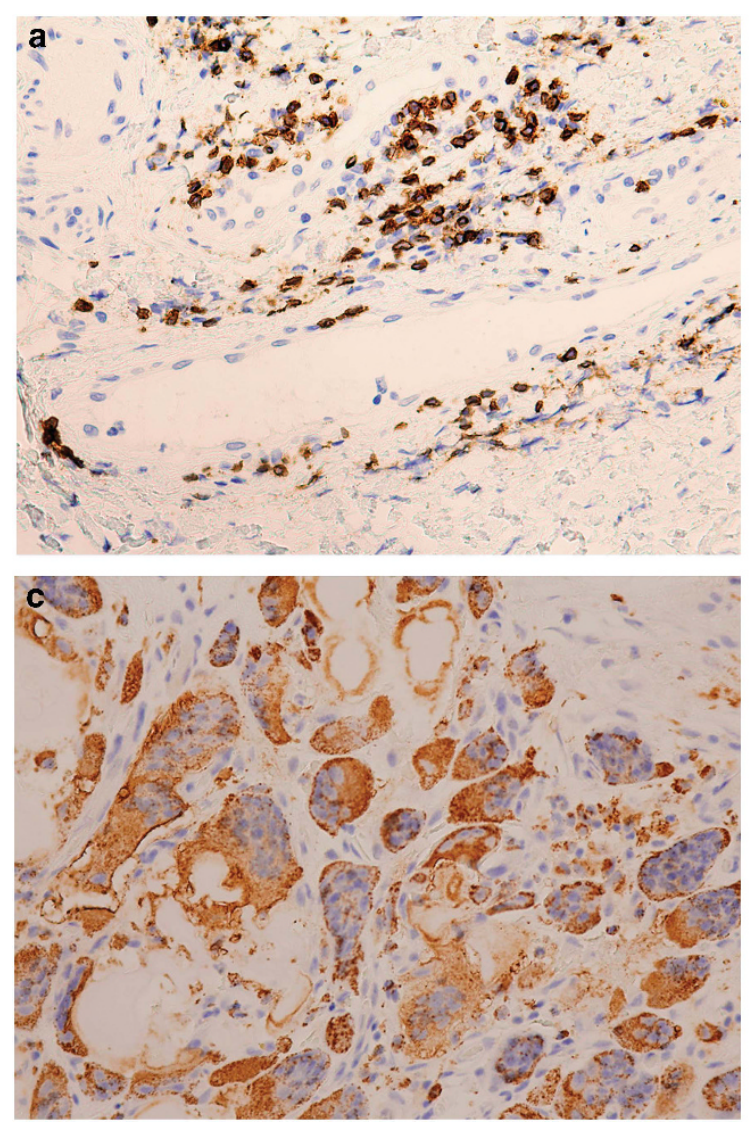

\section{Immunohistochemistry}

Immunostaining for S-100 protein was negative for all the specimens $(n=52)$, revealing a lack of nerve proliferation, Schwann cells, and melanic cells.

Positive immunostaining for CD3, CD34, and CD68 (Figures $2 \mathrm{a}-\mathrm{d}$ ) was found in all the MIRAgel capsule specimens $(n=36)$ from 21 patients and in the conjunctiva specimens $(n=6)$ from 5 patients. The silicone rubber capsule specimens $(n=10)$ from 7 patients exhibited scarce positive immunostaining for CD34 and CD68 (Table 1).
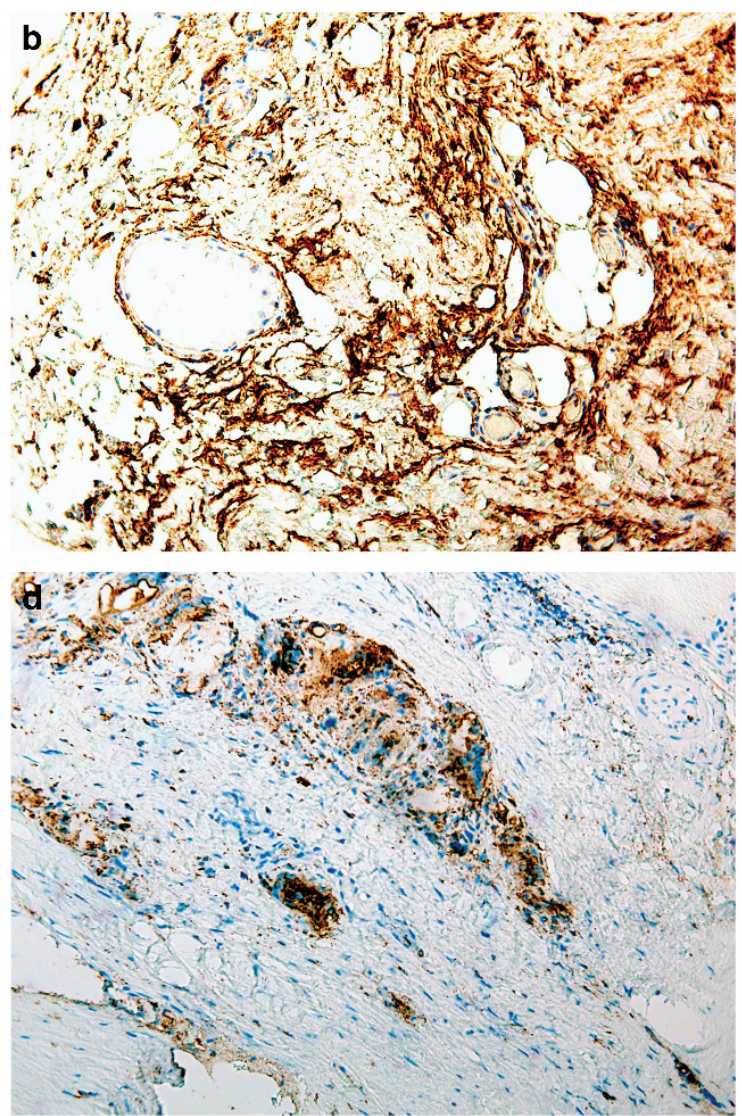

Figure 2 Immunohistochemical study of the capsule of MIRAgel specimens, respectively staining of: (a) CD3 (PAP, $\times 240),(b)$ CD34 $(\mathrm{PAP}, \times 240),(\mathrm{c}) \mathrm{CD} 68(\mathrm{PAP}, \times 400)$, and $(\mathrm{d}) \mathrm{CD} 68(\mathrm{PAP}, \times 200)$.

Table 1 Summary of the histomorphometric results obtained for the capsule tissue surrounding the episcleral material

\begin{tabular}{lcccc}
\hline Biomaterial & $C D 3$ & CD20 & CD34 & $C D 68$ \\
\hline MIRAgel $(n=36)^{\mathrm{a}}$ & $258 \pm 15.63$ & 0.0 & ++ & $365.83 \pm 12.28$ \\
${\text { Silicone rubber }(n=10)^{\mathrm{b}}}^{\mathrm{a}}$ & 0.0 & 0.0 & + & $38.62 \pm 1.74$ \\
-test $^{\mathrm{a}, \mathrm{b}}$ (independent samples) & & & $P<0.001(95 \% \mathrm{CI})$ \\
\hline
\end{tabular}

Abbreviation: CI, confidence interval of the difference. ${ }^{a} \mathrm{MIRA} A \mathrm{el}$. ${ }^{\mathrm{b}}$ Silicone rubber. Values are mean number $( \pm \mathrm{SD})$ of stained cells. The mean number of stained cells in three consecutive microscopic fields $(\times 240)$ were considered for each case. Student's $t$-test shows statistically significant differences between MIRAgel and silicone rubber. 
The lymphocytic inflammatory infiltrate related to the MIRAgel fragments was CD3+ and CD20 - . This finding indicates that the immune system can identify the MIRAgel fragments as a foreign body (after their hydrolytic degradation because of the presence of carboxylic groups) during a delayed T cell-mediated immune response (type IV of Gell and Coombs). ${ }^{16}$

Table 1 summarizes the histomorphometric results obtained for the capsule tissue surrounding the episcleral material.

During the surgical removal of the MIRAgel (21 patients), four patients experienced scleral rupture (SR) because of severe scleral infiltration of the MIRAgel fragments that made the sclera thick and rigid.

All the removed MIRAgel explants $(n=21)$ were broad circumferential $-360^{\circ}$ - explants, and 4 of these explants were under a 240 silicone band. All the removed silicone rubber cerclages $(n=7)$ were 240 silicone bands. After explant removal, the retina remained attached in 15 (72\%) of the MIRAgel patients and all (100\%) the silicone rubber patients, with no significant changes in VA. Two of the MIRAgel patients who had SR developed a vitreous hemorrhage and a new RD (RR) immediately after the removal of the $360^{\circ}$ broad MIRAgel. Other four postoperative RD cases were found during follow-up (6 months) and two of these patients had the MIRAgel under a 240 silicone band.

Table 2 summarizes the histomorphometric results obtained for the capsule tissue of MIRAgel patients with intraoperative SR and/or postoperative RR.

After a 6-month follow-up evaluation, all the eyes with removed silicone rubber exhibited an attached retina, no symptoms, and stable VA. Only 15 eyes with removed MIRAgel $(n=21)$ exhibited an attached retina after the

Table 2 MIRAgel: histomorphometric results obtained for the capsule tissue of patients with intraoperative scleral rupture (SR) and/or postoperative retinal redetachment (RR)

\begin{tabular}{lcc}
\hline Patients with MIRAgel $(\mathrm{n}=21)$ & $\mathrm{CD}$ & $\mathrm{CD} 68$ \\
\hline SR $(n=4)(\mathrm{a})$ & $317 \pm 13.9$ & $387.1 \pm 15.8$ \\
No SR $(n=17)(\mathrm{b})$ & $133 \pm 14.26$ & $341.66 \pm 8.76$ \\
SR+RR $(n=2)(\mathrm{c})$ & $349 \pm 14.1$ & $392.9 \pm 16.2$ \\
RR $(n=4)(\mathrm{d})$ & $367 \pm 13.15$ & $368.59 \pm 11.49$ \\
T-test $(\mathrm{a}, \mathrm{b})$ (independent samples) & $P=0.07$ & $P=0.00001$ \\
& $(95 \% \mathrm{CI})$ & $(95 \% \mathrm{CI})$ \\
& $P=0.19$ & $P=0.09$ \\
T-test $(\mathrm{c}, \mathrm{d})$ (independent samples) & $(95 \% \mathrm{CI})$ & $(95 \% \mathrm{CI})$ \\
&
\end{tabular}

Abbreviation: CI, confidence interval of the difference. Values are mean number $( \pm S D)$ of stained cells. The mean number of stained cells in three consecutive microscopic fields $(\times 240)$ were considered for each case. Student's $t$-test shows statistically significant differences between MIRAgel patients with intraoperative scleral rupture (a) and with no intraoperative scleral rupture (b) as well as between MIRAgel patients who had RR+SR (c) and patients who had only RR (d). 6-month follow-up evaluation with no significant changes in VA. Three eyes required drops to reduce the IOP and four eyes become phthisical. Diplopia disappeared in most of the patients and their eyes become orthophoric. However, persistent ocular motility disturbance was observed in five patients, and five eyes exhibited focal inflammation with redness and discomfort associated with the residual MIRAgel fragments.

\section{Discussion}

We described the histological and immunohistochemical features of the capsule tissue surrounding the MIRAgel episcleral buckles of 21 patients who underwent surgery for rhegmatogenous RD 16-24 years earlier. Inflammation with granulomas primarily related to sutures was found in all the MIRAgel specimens $(n=36)$. Foreign body granuloma with multinucleated giant cells, histiocytes, and macrophages (CD68+) surrounding MIRAgel fragments were also present in all the specimens. The lymphocytic inflammatory infiltrate related to the MIRAgel fragments was CD3+ and CD20 - .

A scleral buckle was obtained through the use of non-absorbable biocompatible materials implanted on the eye's surface. These materials underwent a progressive encapsulation. This encapsulation process is a general phenomenon that occurs around materials implanted within tissues.

The genesis of the capsule is similar to the scarring process and encapsulation represents the final stage of a chronic inflammation. ${ }^{17-19}$ Granuloma was reported with both MIRAgel and silicone rubber, but no foreign body reaction was found with regard to silicone rubber. ${ }^{19}$ Granuloma was found in three specimens (from two patients) in the silicone rubber capsules in our study, without staining for CD3 and scarce CD68+ cells (Table 1). However, these cases had an average implantation duration of only 26 months and the silicone did not exhibit fragmentation.

Hydrolytic degradation (because of the presence of carboxylic groups) with fragmentation is associated with both MAI hydrogel ${ }^{9}$ and MIRAgel ${ }^{10}$ after more than 7 years of implantation.

Our series shows $28 \%$ of retinal redetachment (RR). A wide range of RR has been reported in the literature ${ }^{10,20-23}$ after removal of scleral buckles, reaching as high as 34\%. Reported rates of intraoperative scleral perforation reach $8 \%$ for silicone buckles and range from 0 to $18 \%$ for MIRAgel explants. ${ }^{10,20,24-26}$ Crama and Klevering ${ }^{27}$ in their study of 467 MIRAgel cases reported $11 \%$ of intraoperative scleral perforation or RR. The presence of an active ocular infection (cultures were not reported) and a history of more than one preceding RD procedures were significantly associated in their report with a higher risk 
of scleral perforation during the removal procedure. In our experience, intraoperative SR has been mainly associated with focal areas of severe scleral infiltration of the MIRAgel fragments that made the sclera thick and rigid. The edges of these areas are particularly liable to suffer SR with the surgical maneuvers. The longer implantation duration of our patients can explain a higher change in their scleral consistency with an increased rate of SR (4/21 patients, $19 \%)$. A more aggressive surgery can also explain our high rate of SR, the use of BSS as coadjutant in order to preserve the capsule tissue could be associated with increased scleral pressure during the surgery to remove the MIRAgel fragments.

Intraoperative SR and MIRAgel under a 240 silicone band have shown a higher rate of RR (2/4 patients each, $50 \%$ ) in our patients. Interestingly, the highest number of CD3 $(367 \pm 13.15)$ cells in our series was found in cases of RR. Lymphocytes linked to RR/PVR could be an explanation but in our cases no PVR was found preoperatively. The two cases of SR that developed RR immediately after surgery also showed a high number of CD3 $(349 \pm 14.1)$ and CD68 $(392.9 \pm 16.2)$ cells. Cases with only RR $(n=4)$ showed higher number of CD3 $(367 \pm 13.15)$ cells than cases with $\mathrm{SR}+\mathrm{RR}(n=2)(\mathrm{CD} 3$ : $349 \pm 14.1)$ but with no statistically significant difference (NS) $(P=0.19)$. The number of CD68 cells was lower $(368.59 \pm 11.49)$ for $R R$ cases $(n=4)$ than for $R R+S R$ cases $(n=2)(392.9 \pm 16.2)(P=0.09, \mathrm{NS})$. Cases with SR $(n=4)$ showed higher number of CD3 $(317 \pm 13.9)$ and CD68 $(387.1 \pm 15.8)$ cells than cases without SR $(n=17)$ (CD3: $133 \pm 14.26 ;$ CD68: $341.66 \pm 8.76 ; P=0.07, \mathrm{NS}$, and $P=0.00001$, respectively) (Table 2 ). In our experience intraoperative SR has been mainly associated with focal areas of severe scleral infiltration of the MIRAgel fragments (with high number of CD68+ cells) that made the sclera thick and rigid. The edges of these areas are particularly liable to suffer SR with the surgical maneuvers.

The immunohistochemical analysis of our capsule specimens revealed that once the MIRAgel becomes fragmented (after its hydrolytic degradation), the fragments become embedded by the surrounding tissues (ie, the capsule, sclera, and conjunctiva) and are identified as a foreign body by the immune system (CD3+ cells) during a delayed $\mathrm{T}$ cell-mediated immune response). ${ }^{16}$ The phagocytosis of MIRAgel fragments by macrophages (CD68+ cells) likely triggers and perpetuates local disease.

$\mathrm{T}$ cells, mononuclear cells, and macrophage cells are able to form a specific network by connecting with cytokine and chemotactic factors to promote hyperplasia and proliferation through cell-to-cell interactions.

This study observed CD68+ cells. CD68 is likely a general marker of macrophages (such as M1 and M2 cells). In different microenvironments, macrophages can be induced to mature into different subgroups with disparate molecular and functional characteristics. Macrophages are currently divided into two categories: classically activated macrophages (ie, M1 macrophages) and alternatively activated macrophages (ie, M2 macrophages). ${ }^{28} \mathrm{M} 1$ cells can secrete $\mathrm{NO}$, diverse cytokines, iNOs, and so on; moreover, they can act as inducer cells and effector cells to participate in the killing of pathogens and tumor cells during Th1 immune responses. ${ }^{29} \mathrm{M} 2$ cells can promote vascularization and the formation of lymphatic vessels. ${ }^{30}$ The number of CD68+ cells is closely related to cell proliferation. ${ }^{31,32}$ Macrophages can also regulate the NF- $\kappa \mathrm{B}$ pathway to release numerous cytokines (eg, EGFR, GM-CSF, TGF- $\beta$, and so on) and promote tumorigenesis and development. ${ }^{33-36}$

Herzwig et $a l^{37}$ reported the possible proliferative activity of CD68+ cells (with $\mathrm{Ki} 67$ expression) at the site of inflammation in inflammatory diseases of the ocular adnexa. According to these authors, the distribution of macrophages in classic granulomatous lesions containing only M1 macrophages in the avascular center represents an immune response to foreign bodies, whereas proangiogenic M2 macrophages are located primarily in the surrounding inflammatory tissue and are likely required for the vascularization of inflammatory tissue.

In delayed-type hypersensitivity (DTH; ie, an antibodyindependent cell-mediated immune memory response), $\mathrm{T}$ helper-1 lymphocytes respond to specific antigens by releasing cytokines, some of which activate macrophages. The DTH reaction is antigen- specific and causes erythema and induration at the site of the antigen injection in immunized humans. Moreover, the systemic injection of antigen can cause fever, the synthesis of acutephase proteins, and, in some instances, death. Thus, the MIRAgel material should be removed if possible before hydrolysis and fragmentation in all cases. Because the hydrolyzed MIRAgel becomes gel-like and friable, the residual fragments usually remain 'in situ' or in the orbit with a focal localized inflammation after removal. The phagocytosis of MIRAgel fragments via CD68+ macrophages can stimulate inflammasomes, leading to the proteolytic processing of pre-interleukin (IL)- $1 \beta$ to mature IL- $1 \beta$ that can be released into the extracellular environment to activate proinflammatory signaling cascades in other cells. ${ }^{38}$

We reported previously $7.6 \%$ of symptomatic MIRAgel removal in eyes that had the explants for up to 11 years. ${ }^{10}$ Recently, Crama and Klevering ${ }^{27}$ reported more than 34\% of MIRAgel removal. The median interval between the initial implantation surgery of their patients and the buckle removal was 159 months (range, 54-284 months). We can assume that swelling is something that probably is already ongoing in all cases at some point after 5 years 
of time. The mean implantation duration of our patients was 18.5 years (range, 16-24 years) and all the patients showed clinical pseudotumor caused by MIRAgel swelling because of hydrolytic degradation. Anyway, at the moment all the implanted patients must have MIRAgel for 16 years or more (MIRA Inc. discontinued MIRAgel in 1995 in USA, ${ }^{39}$ but MIRAgel continued to be distributed outside the United States and we used it until the year $2000^{10}$ ). Then, removal of MIRAgel explants before hydrolysis and probably removal of all MIRAgel explants should be considered in order to avoid complications. A significant determination coefficient $\left(r^{2}=0.1933, P=0.0105\right)$ was found in our series between CD3 number (higher risk) and longer duration of MIRAgel. The immunohistochemical analysis revealed that the immune system is able to identify the fragments of MIRAgel (after its hydrolytic degradation) as a foreign body during a $\mathrm{T}$ cell-mediated immune response.

\section{Summary}

\section{What was known before}

- MIRAgel is a scleral buckling material used in retinal reattachment surgery. Swelling and fragmentation 7 to 10 years after implantation with orbital discomfort and diplopia led to the discontinuation of its use in 1995. Prompt removal of the MIRAgel explants was recommended when discomfort and/or fragmentation begins.

\section{What this study adds}

- The immunohistochemical analysis revealed the immune system is able to identify the MIRAgel fragments as a foreign body during a delayed $\mathrm{T}$ cell-mediated immune response. The phagocytosis by macrophages likely triggers and perpetuates local disease. Thus, MIRAgel material should be removed before hydrolysis and fragmentation in all cases.

\section{Conflict of interest}

The authors declare no conflict of interest.

\section{Author contributions}

All three authors designed the project, participated in the analysis of the data, and wrote and reviewed the manuscript. M R-P had full access to all the data in the study and takes responsibility for the integrity of the data and the accuracy of the data analysis.

\section{References}

1 Refojo MF, Natchiar G, Liu HS, Lahav M, Tolentino FI. New hydrophilic implant for scleral buckling. Ann Ophthalmol 1980; 12: 88-92.
2 Ho PC, Chan IM, Refojo MF, Tolentino FI. The MAI hydrophilic implant for scleral buckling: a review. Ophthalmic Surg 1984; 15: 511-515.

3 Tolentino FI, Roldan M, Nassif J, Refojo MF. Hydrogel implants for scleral buckling: long-term observations. Retina 1985; 5: 38-41.

4 Hwang KI, Lim JL. Hydrogel explant fragmentation 10 years after scleral buckling surgery. Arch Ophthalmol 1997; 115: 1205-1206.

5 Gribomont AC. Deterioration progressive des explants episcleraux de type Miragel. Bull Doc Belge Ophthalmol 1999; 271: 57-60.

6 Roldan-Pallares M, del Castillo Sanz JL, Awad- El Susi S, Refojo MF. Long-term complications of silicone and hydrogel explants in retinal reattachment surgery. Arch Ophthalmol 1999; 117: 197-201.

7 Lane JI, Randall JG, Campeau NG, Overland PK, Mc Cannel CA, Matsko TA. Imaging of hydrogel episcleral buckle fragmentation as a late complication after retinal reattachment surgery. AJNR Am J Neuroradiol 2001; 22: 1199-1202.

8 Kawano T, Doi M, Miyamura M, Esaki K, Sasoh M, Uji Y. Extrusion and fragmentation of hydrogel exoplant 11 years after scleral buckling surgery. Ophthalmic Surg Lasers 2002; 33: $240-242$.

9 Marin JF, Tolentino FI, Refojo MF, Schepens CL. Long-term complications of the MAI hydrogel intrascleral buckling implant. Arch Ophthalmol 1992; 110: 86-88.

10 Roldan-Pallares M, Hernandez-Montero J, Llanes F, Fernandez-Rubio JE, Ortega F. MIRAgel episcleral buckles: hydrolytic degradation and long-term observations. Arch Ophthalmol 2007; 125: 511-514.

11 D'Hermies F, Korobelnik JF, Caputo G, Mashour B, Chauvaud D, Pouliquen $Y$ et al. Encapsulation of scleral buckling materials. A study of sixty specimens. Ophthalmology 1998; 105: 1079-1086.

12 Yu S-Y, Viola F, Christoforidis JB, D'Amico DJ. Dystrofic calcification of the fibrous capsule around a hydrogel explant 13 years after scleral buckling surgery: capsular calcification of a hydrogel explant. Retina 2005; 25: 1104-1107.

13 Roldán-Pallarés M, Avila MI, Refojo MF. The use of boric acid solution to help in the removal of biodegraded MIRAgel episcleral buckles. Retina 2005; 25: 90-93.

14 Lane JI, Randall JG, Campeau NG, Overland PK, Overland PK, McCannel CA et al. Imaging of hydrogel episcleral buckle fragmentation as a late complication after retinal reattachment surgery. AJNR Am J Neuroradiol 22: 1199-1202.

15 Sternberg LA, Hardy PH Jr, Cuculis JJ, Meyer HG. The unlabeled antibody enzyme method of immunohistochemistry. Preparation and properties of soluble antigen-antibody complex (horseradish peroxidase PAP-) and its use in identification of spirochetes. J Histochem Cytochem 1970; 18: 315-333.

16 Gell PGH, Coombs RRA(eds) Clinical Aspects of Immunology1st edBlackwell: Oxford, England, 1963.

17 Behling CA, Spector M. Quantitative characterization of cells at the interface of long-term implants of selected polymers. J Biomed Mater Res 1986; 20: 653-666.

18 Imber G, Schwager RG, Guthrie RH Jr, Gray GF. Fibrous capsule formation after subcutaneous implantation of synthetic materials in experimental animals. Plast Reconstr Surg 1974; 54: 183-186. 
19 Vistnes LM, Ksander GA, Kosek J. Study of encapsulation of silicone rubber implants in animals. A foreign body reaction. Plast Reconstr Surg 1978; 62: 580-588.

20 Kearney JJ, Lahey JM, Borirakchanyavat S, Schwartz DM, Wilson D, Tanaka SC. Complications of hydrogel explants used in sclera buckling surgery. Am J Ophthalmol 2004; 137: 96-100.

21 Nuzzi G, Rossi S. Buckle removal in retinal detachment surgery: a consecutive case series. Acta Biomed 2008; 79: 128-132.

22 Lindsey PS, Pierce LH, Welch RB. Removal of sclera buckling elements. Causes and complications. Arch Ophthalmol 1983; 101: 570-573.

23 Chen CJ, Kosek K, Benvenutti E. Outcomes and complications of hydrogel scleral explant removal. Ophthalmic Surg Lasers Imaging 2012; 43: 383-387.

24 Le Rouic JF, Bettembourg O, D'Hermies F, Azan F, Renard G, Chauvaud D. Late swelling and removal of MIRAgel buckles: a comparison with silicone indentations. Retina 2003; 23: 641-646.

25 Nguyen QD, Lashkari K, Hirose T, Pruett RC, McMeel JW, Schepens CL. Erosion and intrusion of silicone rubber scleral buckle. Presentation and management. Retina 2001; 21: 214-220.

26 Unlü N, Kocaoglan H, Acar MA, Aslan BS, Duman S. Intraocular intrusion of a scleral sponge implant. Ophthalmic Surg Lasers Imaging 2003; 34: 223-225.

27 Crama N, Klevering BJ. The removal of hydrogel explants. An analysis of 467 consecutive cases. Ophthalmology 2016; 123: 32-38.

28 Montovani A, Germano G, Marchesi F, Locatelli M, Bismas SK. Cancer-promoting tumor-associated macrophages: new vistas and open questions. Eur J Immunol 2011; 41: 2522-2525.

29 Schmieder A, Michel J, Schonhaar K, Goerdt S, Schledzewski K. Differentiation and gene expression profile of tumor-associated macrophages. Semin Cancer Biol 2012; 22: 289-297.
30 Baay M, Brouwer A, Pauwels P, Peeteers M, Lardon F. Tumor cells and tumor-associated macrophages: secreted proteins as potential targets for therapy. Clin Dev Immunol 2011; 2011: 565187.

31 Liu Y, Fan L, Wang Y, Li P, Zhu J, Wang L et al. Tumorassociated macrophages promote tumor cell proliferation in nasopharyngeal NK/T-cell lymphoma. Int J Clin Exp Pathol 2014; 7(9): 5429-5435.

32 Nakagawa J, Saio M, Tamakawa N, Suwa T, Frey AB, Nonaka $\mathrm{K}$ et al. TNF expressed by tumor-associated macrophages, but not microglia, can eliminate glioma. Int J Oncol 2007; 30: 803-811.

33 Mantovani A, Sica A. Macrophages, innate immunity and cancer: balance, tolerance, and diversity. Curr Opin Immunol 2010; 22: 231-237.

34 Feng HC, Song YF, Wen YM. Correlation between expression of vascular endothelial factor-C in tumorassociated macrophages and lymphatic metastasis in oral cancer. Ai Zheng 2004; 23: 278-281.

35 Hemmerlein B, Markus A, Wehner M, Kugler A, Zschunke F, Radzum HJ. Expression of acute and late-stage inflammatory antigens, cfms, CFS- 1 , and human monocytic serine esterase 1, in tumor-associated macrophages of renal cell carcinomas. Cancer Immunol Immmunother 2000; 49: 485-492.

36 Sica A. Role of tumor-associated macrophages in cancerrelated inflammation. Exp Oncol 2010; 32: 153-158.

37 Herzwig MC, Holz FG, Loeffler KU. Distribution and presumed proliferation of macrophages in inflammatory diseases of the ocular adnexae. Curr Eye Res 2015; 40: 604-610.

38 Masters SL, O'Neill LA. Disease-associated amyloid and misfolded protein aggregates activate the inflammasome. Trends Mol Med 2011; 17: 276-282.

39 Farley D. Device firm closes pending compliance with FDA regulations. FDA Consumer 1995; 29: 32. 